\title{
Social Competence in Persons with Prader-Willi, Williams and Down's Syndromes
}

\author{
Beth A. Rosner*, Robert M. Hodapp ${ }^{\dagger}$, Deborah J. Fidler*, Jaclyn N. Sagun* and Elisabeth M. Dykens ${ }^{\dagger}$ \\ *Neuropsychiatric Institute, University of California, Los Angeles, CA, USA, \\ ${ }^{\dagger} J o h n$ F. Kennedy Center \& Peabody College, Vanderbilt University, Nashoille, TN, USA, \\ ${ }^{\ddagger}$ College of Applied Human Sciences, Colorado State University, Fort Collins, CO, USA
}

Accepted for publication 18 February 2004

Background This study explores everyday social competence in the lives of persons with three genetic intellectual disability syndromes.

Methods Using parent reports on the Social and Activity Competence domains of Achenbach's Child Behavior Checklist $(\mathrm{CBCL})$, socially competent behaviours were examined in 58 persons with Williams syndrome, 54 persons with Prader-Willi syndrome, and 65 persons with Down's syndrome.

Results The Down's syndrome group showed the highest overall social competence scores, while individuals with Prader-Willi syndrome fared worst in terms of their behaviour with others. The Williams syndrome group scored lowest in terms of skill with jobs and chores, and the Down's syndrome group showed the least skill in non-sport activities. Regarding specific activities, musi- cal activities were popular in both Williams syndrome and Down's syndrome, but more participants with Williams syndrome played musical instruments. Compared with the other groups, individuals with Prader-Willi syndrome were five to 25 times more likely to play with jigsaw puzzles, and those with Williams syndrome were least likely to engage in any visual-spatial leisure activities. Age was found to be a positive correlate of social competence for the Williams and Down's syndrome groups, but not for the Prader-Willi group.

Conclusions Implications are discussed for interventions and for future behavioural phenotype work.

Keywords: Down's syndrome, music, Prader-Willi syndrome, social competence, visual-spatial leisure activities, Williams syndrome

\section{Introduction}

Consistent with a renewed focus on the positive behaviours of persons with intellectual disability, many researchers are examining social competence. Although the term has been variously defined (e.g. Zigler \& Trickett 1978; Greenspan \& Granfield 1992), most measures of social competence assess the number and quality of a person's jobs, chores, friends, clubs, and hobbies (Achenbach 1991). Focusing on such positive, competent behaviours ultimately helps persons with intellectual disability 'to become contributing members within the social fabric of the family, school, and community' (Siperstein 1992, p. iv).

Given the importance of socially competent behaviours for optimal everyday functioning, it is surprising that very few social competence studies focus on persons with intellectual disability. These few existing childhood studies examine only limited aspects of social competence, such as children's perceptions of their own competencies (e.g. Widaman et al. 1992; Williams \& Asher 1992). Such limited emphases within the intellectual disabilities field contrast with the long history of examining social competence in typically developing children. As a part of his Child Behavior Checklist (CBCL), Achenbach (1991) has derived precise norms and clinical cut-off scores in several social competence domains for children aged 6-18 years.

Social competence studies in intellectual disabilities have also been limited by the use of mixed or heterogeneous samples. Although such 'mixed group' behavioural studies remain widespread in the field (Hodapp \& Dykens 1994), increasing evidence suggests distinctive cognitive-behavioural profiles in several genetic intellectual disability syndromes. Thus, it seems timely to examine if and how cognitive-behavioural profiles impact social behaviour in particular disorders.

To that end, this study assesses social competence in individuals with three genetic syndromes: Prader-Willi, 
Williams and Down's syndrome. These syndromes were chosen because they have well-established behavioural phenotypes (Dykens et al. 2000), that differ markedly from each other across several domains including language, visual-spatial skill, sociability, and maladaptive behaviour. As such, we expect results from this study to show differences in the relationship between these syndromes, associated phenotypes, and competent behaviours.

Relative to other genetic intellectual disability syndromes, persons with Prader-Willi syndrome possess high levels of intelligence, often falling in the mild range of cognitive delay. Visual processing is a relatively strong cognitive skill (Dykens et al. 1992), and children and adolescents with this syndrome excel on visual-motor tasks such as arranging triangles to match an abstract design. Consistent with these strengths, children with PraderWilli syndrome have shown a remarkable facility with jigsaw puzzles, even outperforming age-matched peers with average intelligence quotient (IQ) (Dykens 2002).

In contrast to these cognitive strengths, people with Prader-Willi syndrome commonly show high rates of behavioural difficulties (Einfeld et al. 1999). These problems include underactivity, hyperphagia, compulsions, stubbornness, and aggressive behaviour. They are less interested in physical activities than others with intellectual disability, and also struggle socially by being teased and disliked by peers (Dykens \& Rosner 1999; Dykens et al. 2000). Given this profile, we expect that participants with Prader-Willi syndrome to be more competent in solitary activities than sports or social pursuits, with a preference towards puzzles and other activities that make use of their visual-motor skills. It is also likely that maladaptive behaviour will interfere with everyday social competence in this group.

Williams syndrome has been the focus of recent research, in part, because of its intriguing cognitive profile. Despite the overall IQ scores being in the 50-60 range (Plissart et al. 1994), persons with Williams syndrome demonstrate remarkable skills in expressive vocabulary, syntax, and semantics (Udwin \& Yule 1990; Bellugi et al. 1994). Case reports suggest that persons with Williams syndrome also show exceptional musical talent, although findings regarding their level of skill are mixed (Levitan \& Bellugi 1998; Don et al. 1999). On the contrary, persons with Williams syndrome generally show extreme deficits in visual-spatial processing required for tasks such as drawing (Bellugi et al. 1994).

Several maladaptive behaviours are also commonly associated with this disorder. These include anxiety and fears, preoccupations, hyperactivity, distractibility, and heightened sensitivities to certain sounds (hyperacusis)
(Einfeld et al. 1997; Dykens 2003). Moreover, while persons with Williams syndrome have a very sociable personality style (Dykens \& Rosner 1999), interpersonal difficulties such as overfriendliness, social disinhibition, and poor peer relationships are often reported (Davies et al. 1998). Hence, the Williams syndrome group is inclined towards activities involving language and music but, overall, should score low on social competence measures involving peers.

Of the three groups under study, persons with Down's syndrome tend to attain the lowest cognitive levels, usually in the moderate range of delay. However, many persons with Down's syndrome show significant, relative strengths in tasks assessing visual memory and visualmotor skill (Hodapp et al. 1999; Dykens et al. 2001). Moreover, young children with Down's syndrome show relative strengths in gestural-symbolic activities such as 'talking' into a toy telephone (Harris et al. 1997; Beeghly 1998). These strengths make persons with Down's syndrome ideal candidates for instruction in sign language (Freeman \& Hodapp 2000) and reading (Buckley 1999). Relative weaknesses in Down's syndrome are typically found in expressive language, articulation, and linguistic grammar (Fowler 1990; Miller et al. 1995).

Behaviourally, persons with Down's syndrome are often described as charming, social, friendly and engaging (Dykens et al. 2000). While inattention, stubbornness, and non-compliance are common behaviour problems (Cuskelly \& Dadds 1992; Dykens et al. 2002), children and adults with Down's syndrome show lower rates of emotional and behaviour problems when compared to others with intellectual disability (Dykens \& Kasari 1997; Einfeld et al. 1999). Given this profile of sociability combined with low rates of negative behaviours, we expect persons with Down's syndrome to score relatively well on measures of social competence. Moreover, given their strengths in visual-spatial and symbolic processing, we predict that participants with Down's syndrome will show an interest in visual-motor activities and pretend play.

Thus, given the differences in their cognitive and behavioural phenotypes, we predict that individuals with Prader-Willi, Williams, and Down's syndromes will show different profiles of socially competent behaviours. To that end, we performed three sets of analyses. First, we compared groups on both global and more specific social competence domains from Achenbach's CBCL. Second, we identified the actual content of activities to determine if favourite activities mirror such proposed aetiology-related strengths such as puzzle play in Prader-Willi syndrome, musical activities in Williams 
syndrome, and visual and symbolic activities in Down's syndrome. Third, we looked within groups to identify which variables (e.g. age, gender, IQ, maladaptive behaviours) might relate to socially competent functioning.

\section{Method}

\section{Participants}

Participants included 177 persons aged 4-49 years who belonged to one of three groups: Prader-Willi syndrome $(n=54)$; Williams syndrome $(n=58)$; and Down's syndrome $(n=65)$. Groups were equal in terms of gender $\left(\chi_{1}^{2}=1.72 ; n=177 ; \quad n s\right) \quad$ and ethnicity $\quad\left(\chi_{2}^{2}=2.17\right.$; $n=177 ;$ ns). In addition, equal across groups were such family demographic variables as parent age and education, number of siblings, and family income. As Table 1 shows, parents were primarily of middle-class and college-educated. Because participants with Down's syndrome were, on average, 4-5 years younger in age and 12-16 points lower in IQ than the other two groups, both age and IQ were used as co-variates in all between-group analyses. All participants had undergone molecular genetic testing that confirmed their diagnoses.

\section{Procedures}

Participants were recruited through parent groups for the syndromes under study and Regional Centers in the Los Angeles area. Parents indicated interest in our studies through their responses to direct solicitations at annual conferences, to advertisements in organizational newsletters, and to large-scale mailings to organization members. The majority of respondents were mothers.
Respondents completed the research questionnaires at home or as part of the research visit. All participants were individually administered the test battery by trained research assistants.

\section{Measures}

The Kaufman Brief Intelligence Test (K-BIT; Kaufman \& Kaufman 1983) was administered to all participants. The $\mathrm{K}$-BIT is a brief, individually administered measure of verbal and non-verbal intelligence for individuals aged 4-90 years. The measure provides standard scores for the Vocabulary and Matrices subtests, as well as a composite IQ. The K-BIT has been successfully used in previous studies of children and adults with intellectual disabilities (Dykens et al. 2001).

Demographic information collected on all participants included parental age, education, and income, family size, ethnicity, and gender.

Social competence, as measured by the CBCL (Achenbach 1991), reflects the number and quality of various activities and relationships. Respondents are asked to list various activities pursued by their child, and to rate their child's skill and participation in each activity, and how well their child gets along with others. These items are coded according to criteria set forth by Achenbach (1991) and summed to produce two domain scores: 'activity competence' and 'social competence'. The CBCL also includes a third domain, 'school competence', in which parents are asked to rate their child's performance in academic subjects. As many individuals were either past the school years or did not attend mainstream classes, we did not include the school-related items in our analyses.

Table I One-way ANOva of demographic variables

\begin{tabular}{|c|c|c|c|c|}
\hline & PWS [mean (SD)] & WS [mean (SD)] & DS [mean (SD)] & $F$-value \\
\hline Subject chronological age & $16.37(8.31)$ & $17.41(10.88)$ & $12.36(6.23)$ & $5.93^{*}$ \\
\hline Subject K-BIT IQ & $64.78(14.95)$ & $61.66(15.84)$ & 48.77 (10.93) & $22.64^{* *}$ \\
\hline Mother's chronological age & $45.08(9.85)$ & $46.30(11.09)$ & $43.24(8.10)$ & 1.51 \\
\hline Father's chronological age & $46.67(9.73)$ & $48.26(12.33)$ & $45.54(8.03)$ & 1.01 \\
\hline Mother's education $^{1}$ & $3.19(1.27)$ & $3.41(1.26)$ & $3.48(1.15)$ & 0.89 \\
\hline Father's education ${ }^{1}$ & $3.56(1.24)$ & $3.46(1.30)$ & $3.93(1.14)$ & 2.41 \\
\hline Number of siblings & $1.41(1.02)$ & $1.64(1.04)$ & $1.76(1.14)$ & 0.91 \\
\hline Family income ${ }^{2}$ & $4.12(1.41)$ & $4.22(1.29)$ & $4.64(1.43)$ & 2.35 \\
\hline
\end{tabular}

\footnotetext{
${ }^{1}$ Education: 1, some high school; 2, high school degree; 3, 2-year degree; 4, 4-year degree; 5; graduate or professional degree. ${ }^{2}$ Income: $1,<\$ 15000 ; 2, \$ 15000-\$ 29000 ; 3, \$ 30$ 000-\$49 000; 4, \$50 000-\$69 000; 5, \$70 000-\$99 000; 6, \$100 $000+$. $* P<0.01 ; * * P<0.001$.
}

PWS, Prader-Willi syndrome; WS, Williams syndrome; DS, Down's syndrome. 
The 'activity domain' consists of the number of sports in which the individual is engaged, the frequency of participation and skill in sports, skill in non-sport hobbies and games, the number of paid or unpaid jobs or chores, and the quality of job-chore performance. The CBCL also measures the number of non-sport activities, although this score is not included in the 'activity domain' score. The 'social domain' rates the number and degree of participation in clubs or organizations, the number of close friends and the degree of contact with them, how well the individual gets along with peers and family members, and how well the individual plays and works alone.

As part of the 'activity domain', respondents were asked to list non-sport activities that their child enjoys. These responses were coded for content by two independent raters. Raters indicated whether each response fell into one of the following categories: (1) 'music' (e.g. listening to music, playing an instrument, dancing, singing); (2) 'reading' magazines or books; (3) 'visual-motor activities' such as puzzles, word search/activity books, computer/electronic games, arts and crafts, drawing, or painting; (4) 'physical activities not considered sports' (e.g. walking, aerobics, trampoline); (5) 'pretend play' such as playing with dolls, action figures, or playing house; and (6) 'focused, specific interests', such as rock collecting and rodeo magazines. These categories reflect responses that were reported by at least $20 \%$ of any one group. Responses that were reported by $<20 \%$ of any one group were bunched together and coded as 'other'.

Using two independent raters, inter-rater reliability for each category was calculated using Cohen's kappa (Cohen 1960; Rigby 2000). Kappa values ranged from 0.78 (for 'physical activities') to 0.98 (for 'reading and visual-motor' activities), with a mean value of 0.90 . Kappa values above 0.75 are considered 'excellent' reliability (Cicchetti 1994).

For maladaptive behaviour, we measured internalizing, externalizing, and overall pathology across eight narrow band domains: 'withdrawn', 'somatic complaints', 'anxious/depressed', 'social problems', 'attention problems', 'aggressive behaviour', and 'delinquent behaviour'. The CBCL consists of 112 maladaptive items (e.g. impulsive or acts without thinking) that are rated according to a three-point scale ( 0 , not true; 1 , somewhat or sometimes true; 2, very true or often true). The CBCL's reliability and validity have been well established, and the instrument has been successfully used in previous studies of persons with intellectual disabilities.

\section{Results}

\section{Cross-group comparisons}

\section{Social competence}

The results indicate a main effect for overall Social Competence Domain Score $[F(2,170)=3.37, P<0.05]$, with the Down's syndrome group showing higher scores than the other two groups. Moreover, follow-up ANcovA revealed group differences on specific items of the social domain. Specifically, participants with Down's syndrome were more active in organizations than members of the Prader-Willi group $[F(2,175)=4.91, P<0.01]$. In addition, behaviour with others was rated more positively in the Down's and Williams groups than in the Prader-Willi group $[F(2,177)=5.36, P<0.01]$. Compared with the Williams and Down's syndrome groups, participants with Prader-Willi syndrome were more often rated in the 'below-average' range in their behaviour with others (21\% and $17 \%$ vs. $35 \%$, respectively) $\left(\chi_{2}^{2}=5.88 ; n=177 ; P=0.053\right)$.

\section{Activity competence}

Although the three groups did not differ on the overall measure of 'activity competence' $[F(2,174)=2.41$; ns $]$, closer analyses revealed strong between-group differences on individual items. For example, individuals with Williams syndrome scored lowest in job quality $[F(2,175)=6.02, P<0.01]$, with a full $72 \%$ receiving a 'below-average' job quality rating (compared with $46 \%$ and $43 \%$ for individuals with Down's and Prader-Willi syndromes, respectively) $\left(\chi_{2}^{2}=12.34 ; n=175 ; P<0.01\right)$. Persons with Williams syndrome also scored lower than the Prader-Willi group in their number of non-sport activities $[F(2,175)=3.59 ; P<0.05]$. In contrast, the group with Down's syndrome was rated lowest in skill and time spent in activities $[F(2,175)=5.96 ; P<0.01]$. Over half $(57 \%)$ of persons with Down's syndrome were rated as below-average in skill-time spent in activities, compared with only $37 \%$ and $23 \%$ of the Williams and Prader-Willi groups, respectively $\left(\chi_{2}^{2}=14.65 ; n=175\right.$; $P<0.001$ ). (See Table 2 for the aetiology by mean scores on the CBCL activity and social domains.)

\section{Content of activities}

To determine whether favourite activities mirror documented strengths in each group, chi-square analyses were performed on parent report of seven types of 
Table 2 CBCL activities and social domain scores, by aetiology

\begin{tabular}{|c|c|c|c|c|c|}
\hline \multirow[b]{2}{*}{ Domain } & \multicolumn{3}{|c|}{ Aetiology } & \multirow[b]{2}{*}{$F$-value } & \multirow[b]{2}{*}{ Groups differing: } \\
\hline & PWS & WS & DS & & \\
\hline No. sports & 1.07 & 1.02 & 1.23 & 0.95 & \\
\hline Participation/skill in sports & 0.45 & 0.49 & 0.57 & 2.07 & \\
\hline No. non-sport activities & 1.56 & 1.09 & 1.29 & $3.59^{*}$ & $\mathrm{PW}>\mathrm{WS}$ \\
\hline Participation/skill in activities & 1.22 & 0.99 & 0.79 & $5.96^{* *}$ & PWS and WS > DS \\
\hline No. jobs & 1.13 & 1.07 & 1.05 & 0.32 & \\
\hline Job quality & 0.75 & 0.47 & 0.72 & $6.02^{* *}$ & PWS and DS $>$ WS \\
\hline No. organizations & 0.39 & 0.26 & 0.37 & 0.93 & \\
\hline Participation in organizations & 0.41 & 0.40 & 0.57 & $4.91^{* *}$ & DS > PWS and WS \\
\hline No. friends & 0.69 & 0.66 & 0.86 & 1.22 & \\
\hline Contact with friends & 0.46 & 0.60 & 0.60 & 0.61 & \\
\hline Behaviour with others & 0.94 & 1.09 & 1.20 & $5.36^{* *}$ & WS \& DS > PWS \\
\hline Behaviour alone & 1.24 & 1.07 & 1.25 & 1.44 & \\
\hline
\end{tabular}

${ }^{*} P<0.05 ;{ }^{* *} P<0.01$.

PWS, Prader-Willi syndrome; WS, Williams syndrome; DS, Down's syndrome.

favourite activities. As shown in Table 3, a higher percentage of the Williams and Down's syndrome groups engaged in musical activities than did the Prader-Willi group. Conversely, in line with their visual-motor difficulties, fewer persons with Williams syndrome engaged in 'visual-motor' and 'pretend play' activities.

To clarify the group differences in musical and visual-motor activities, categories were further broken down into more specific activities. As we hypothesized that the Williams syndrome group would be more involved in playing instruments, we coded whether musical activities involved (1) playing a musical instrument or (2) non-instrument activities such listening to music, dancing, and singing. As expected, the group with Williams syndrome group stood out in their interest in playing instruments $\left(\chi_{2}^{2}=7.62\right.$; $n=177 ; P<0.01$ ), with $21 \%$ of these individuals playing a musical instrument, whereas only $11 \%$ and $5 \%$ did so among persons with Prader-Willi and Down's syndromes, respectively. When looking at non-instrument musical activities, we found that higher proportions of both the Williams (28\%) and Down's syndrome groups $(43 \%)$ - compared with those with Prader-Willi syndrome (15\%) - enjoyed dancing, singing, and listening to music $\left(\chi_{2}^{2}=11.49 ; n=177\right.$; $P<0.01)$.

Visual-motor activities were also coded more specifically into one of three categories to better understand participation: (1) puzzles, (2) electronic/computer games, and (3) arts and crafts. As expected, chi-square
Table 3 Percentage participating in each activity content area

\begin{tabular}{lllll}
\hline Content & PWS (\%) & WS (\%) & DS (\%) & Chi-squared value \\
\hline Music & 20 & 43 & 43 & $8.39^{*}$ \\
Reading & 30 & 33 & 42 & 1.97 \\
Visual-motor & 76 & 31 & 60 & $23.70^{* * *}$ \\
Athletics & 19 & 9 & 12 & 2.47 \\
Pretend Play & 19 & 3 & 17 & $7.02^{*}$ \\
Focused Interest & 20 & 26 & 5 & $11.00^{* *}$ \\
Other & 15 & 28 & 26 & 3.08 \\
\hline
\end{tabular}

${ }^{*} P<0.05 ;{ }^{* *} P<0.01 ;{ }^{* * *} P<0.001$.

PWS, Prader-Willi syndrome; WS, Williams syndrome; DS,

Down's syndrome.

analyses revealed that puzzles were listed as an activity for a full $50 \%$ of person with Prader-Willi syndrome, compared with only $9 \%$ and $2 \%$ of persons with Down's or Williams syndrome $\left(\chi_{2}^{2}=48.56 ; n=177 ; P<0.001\right)$. In line with their low rates of puzzle participation, persons with Williams syndrome also showed extremely low levels of participation in arts and crafts (e.g. 5\%), compared with rates of $30 \%$ and $35 \%$ for the PraderWilli and Down's syndrome groups, respectively $\left(\chi_{2}^{2}=16.95 ; n=177 ; P<0.001\right)$.

\section{Correlates of social competence}

To identify which personal characteristics relate to various social competence measures, we next looked at 
gender, IQ, age, and maladaptive behaviour. Surprisingly, no effects for gender or IQ were found for the 'activity' or 'social competence' domain scores for the sample as a whole or any of the three groups. In contrast, both chronological age and degree of maladaptive behaviour showed important correlations with various measures of social competence.

\section{Age}

Higher 'social competence' domain scores were moderately associated with increasing chronological age in groups with both Williams syndrome $[r(54)=0.39$; $P<0.01]$, and Down's syndrome $[r(65)=0.34$; $P<0.01$ ]; 'activity competence' scores also increased with age in the Down's syndrome group $[r(65)=0.30$; $P<0.05]$. In sharp contrast, no relationships with increasing age were found in the group with PraderWilli syndrome, where the correlations of age with the 'social competence' domain were 0.002 (ns), and with the 'activity competence' domain were 0.20 (ns).

\section{Maladaptive behaviour}

As shown in Table 4, for each group, the 'social competence' domain score was negatively correlated with the externalizing domain of the CBCL. A similar relationship between the 'social competence' domain and the CBCL total score was found for the Williams and Down's syndrome groups. Also, the 'social competence' domain correlated negatively with the internalizing domain for the Prader-Willi syndrome group. In sharp contrast, no significant correlations occurred between the 'activity competence' domain and CBCL total scores for any group ( $r=-0.02$ to 0.08 ).

Table 4 Correlations between social functioning and CBCL maladaptive scores, by aetiology

\begin{tabular}{llll}
\hline \multicolumn{4}{l}{ Aetiology } \\
\cline { 2 - 4 } Social domain by maladaptive scores & $P W S$ & WS & DS \\
\hline CBCL total & -0.33 & $-0.34^{*}$ & $-0.29^{*}$ \\
Internalizing & $-0.32^{*}$ & $-0.19^{*}$ & -0.11 \\
Externalizing & $-0.50^{* * *}$ & $-0.35^{*}$ & $-0.29^{*}$ \\
\hline
\end{tabular}

${ }^{*} P<0.05 ;{ }^{* *} P<0.01 ;{ }^{* *} P<0.001$.

PWS, Prader-Willi syndrome; WS, Williams syndrome; DS, Down's syndrome.

\section{Discussion}

Although the behavioural phenotypes of different genetic disorders have been well established using standardized laboratory tests, this study shows how phenotypes are clearly reflected in the everyday behaviour of persons with Prader-Willi, Williams, and Down's syndromes. These findings thus add a practical, everyday dimension to the Prader-Willi, Williams, and Down's syndrome behavioural phenotypes, and suggest several areas of future work.

For Prader-Willi syndrome, findings highlight both the activities and interpersonal problems often found in this group. Specifically, the group with Prader-Willi syndrome participated more in non-sport activities than the other two groups. When examining the specific content of these activities, we found that over three-quarters of the Prader-Willi participants engaged in tasks involving visual-motor skills, and half engaged in jigsaw puzzles. These findings are in line with recent research showing that many individuals with Prader-Willi syndrome are indeed excellent - even better than typical children of the same chronological age - in solving jigsaw puzzles (Dykens 2002). Hence, it is perhaps not surprising that so many persons with this disorder gravitate towards visual-spatial activities in general, jigsaw puzzles in particular.

However, the Prader-Willi group fared worst in behaviour with others, and was less active in social organizations (at least when compared with those with Down's syndrome). Moreover, and in contrast to the other two groups, the group with Prader-Willi syndrome did not increase in social competence as they got older.

Such findings move earlier, more laboratory-based findings on Prader-Willi syndrome into everyday life functioning, and suggest that targeting maladaptive behaviour may be the most effective course to increasing social competence in this group. Historically, the presence of hyperphagia, over-eating, and excessive weight have led to concerns about getting people with the syndrome to engage in tasks that might go beyond non-sport activities. At the same time, the presence of tantrums has often hindered these individuals' relationship with others (Dykens \& Kasari 1997), leading to increased levels of parent-family stress (Hodapp et al. 1997). This increased risk for behavioural and social difficulties across the lifespan underscores the need for management and care for persons with Prader-Willi syndrome that also extends over the long term (Dykens \& Cassidy 1996). 
Although musicality is a relatively under-researched aspect of the Williams syndrome behavioural phenotype, findings from this study are in line with reports that children with Williams syndrome show relative strength in this area, as well as a greater liking of music than typically developing children (Don et al. 1999). In particular, we found that individuals with Williams syndrome oftentimes take up music, and even play musical instruments, at a much higher rate than persons with Prader-Willi and Down's syndromes.

However, the Williams syndrome group scored lowest in job skills, which on the CBCL includes both chores and jobs outside the home. Again, these findings about everyday life mirror documented findings about Williams syndrome. Specifically, studies have noted that children and adults with Williams syndrome show weaknesses in adaptive living skills (Plissart et al. 1994; Mervis et al. 2001), and adults have particular difficulty coping with the demands of employment (Udwin et al. 1998). Occupational problems include interference from their distractibility, social disinhibition and overfriendliness, and anxiety (Davies et al. 1997). Poor visual-motor skills required in many chores (making beds, washing dishes) and entry-level jobs (stacking, sorting, assembly-line work) may also be a source of difficulty. As such, many adults with Williams syndrome may require the ongoing and sustained support of job coaches (Dykens et al. 2000). Working adults may also do better with people-oriented jobs that rely less on motor skills and more on their interest in others. Finally, these findings imply that occupational therapists may have a continuing role in helping persons with Williams syndrome gain enough fine motor skills for daily chores.

Participants with Down's syndrome displayed a pattern of high sociability and low skill in non-sport activities. Specifically, individuals with Down's syndrome behaved well with others, were active in organizations, and showed a fair amount of job skill. Like Williams syndrome participants, they shared an interest in music, although the Down's syndrome group was more likely to engage in dancing, singing, and listening to music than playing an instrument. Similarly, as expected, and like the Prader-Willi group, a high percentage of participants with Down's syndrome (60\%) engaged in visualmotor activities. However, their inclination within this category was towards arts and crafts and they tended to stay away from puzzles.

Such findings are in line with earlier studies of adaptive behaviour that document relative strengths in socialization and daily living skills in children with
Down's syndrome (Dykens et al. 1994). Certainly, it may be their cheerful, sociable personality style (Wishart \& Johnston 1990; Hornby 1995) and their relatively low rate of maladaptive behaviours (Dykens \& Kasari 1997; Einfeld et al. 1999) that underlies these social competencies. On the other hand, the relatively lower skill level reported in non-sports activities suggests that, despite their strengths in visual-motor skills, persons with Down's syndrome may benefit from recreational therapy, as well as additional support when engaging in activities alone.

Taken together, these findings raise questions about the meaning, origins, and uses of syndrome-specific 'favourite' activities. With the exception of, for example, symbolic play in Down's syndrome, most of the hypothesized aetiology-related activities were more common in the predicted group. Thus, greater percentages of children with Williams syndrome played musical instruments, and higher scores on non-sport activities - especially working on jigsaw puzzles - were noted in the group with Prader-Willi syndrome. In addition, our findings also reflect the 'negative choice' of certain activities; hence the lack of visual motor activities by children with Williams syndrome.

Such findings bring forth a host of questions concerning why and how such aetiology-related activities develop. Why, for example, are children with Williams syndrome playing musical instruments and not engaging in visual-spatial activities? Why do children with Prader-Willi syndrome choose puzzles? Are such choices made or helped along by parents (and parental knowledge of the 'lore' of various syndromes), or by the child's own beginning understanding that they are good at one activity and poor at another? Do such understandings change with age? Given the CBCL's relatively crude measurement of everyday activities, we could not address such issues, but future studies might examine the development of both the activities themselves and the reasons behind taking up such activities.

An additional question concerns how parents and service providers can use this information. In many ways, knowledge that a child is good at, say, music or puzzles, provides parents with one of the few bits of 'good news' about their child, something that their child can - as opposed to cannot - do. But should educators and service providers then make use of these interests to promote learning and social competence? Or should parents and service providers simply allow such activities to remain as hobbies and passions? In short, when dealing with persons with different genetic syndromes, can specific activities be 'left alone' or can (or should) 
such activities be employed in intervention? These are questions that we grapple with as we seek to minimize maladaptive behaviours and maximize socially competent strengths in persons with these three syndromes.

While findings of this study offer insights into aetiology-related differences in social competence, certain caveats need to be mentioned. First, while the CBCL is a standardized, well-used instrument in both research and clinical settings, the social competence section is a fairly gross measure that has not been widely used in persons with intellectual disability. Moreover, syndrome-specific profiles were not directly measured for each individual in this study. Undoubtedly, at least some participants with each syndrome did not show the 'typical' cognitive-behavioural strengths or weaknesses associated with each group as a whole (Dykens 1995). Similarly, as in most studies using these three aetiology groups, we too recruited participants through the relevant parent organizations, which may have introduced certain biases that go beyond the three groups' comparability on parent education and income levels. Overall, then, while we feel confident that a reasonably representative sample of each disorder was obtained, future studies may benefit from directly assessing syndrome-specific profiles and from recruiting subjects from a wider array of sources.

It is also important to mention that the Down's syndrome group was not screened for Alzheimer's dementia. Although that group included only eight individuals above age 20 years (for whom dementia might possibly be an issue), future social-competence studies of adults with Down's syndrome should include a dementia assessment.

Nevertheless, this study begins the process of describing how everyday social competence varies among persons with different genetic intellectual disability syndromes. Awareness of these different social competence profiles may be useful for families and professionals as they plan and implement recreational activities, educational programmes, and vocational goals. Although the ultimate - and appropriate - use of such information remains unclear, this study moves what had earlier been solely 'laboratory-based' findings about behavioural phenotypes into the realm of everyday life.

\section{Correspondence}

Any correspondence should be addressed to Dr Robert M. Hodapp, Department of Special Education, Peabody College \& John F. Kennedy Center on Research in Human Development, Peabody Box 328, Nashville, TN 37203, USA (e-mail: robert.hodapp@vanderbilt.edu).

\section{References}

Achenbach T.M. (1991) Manual for the Child Behavior Checklist/ 4-18 and 1991 Profile. University of Vermont, Department of Psychiatry, Burlington, VT.

Beeghly M. (1998) Emergence of symbolic play: perspectives from typical and atypical development. In: Handbook of Mental Retardation and Development (eds J.A. Burack, R.M. Hodapp \& E. Zigler), pp. 240-289. Cambridge University Press, Cambridge.

Bellugi U., Wang P. \& Jernigan T.L. (1994) Williams syndrome: an unusual neuropsychological profile. In: Atypical Cognitive Deficits in Developmental Disorders (eds S.H. Browman \& J. Grafram), pp. 23-56. Erlbaum, Hillsdale.

Buckley S. (1999) Promoting the cognitive development of children with Down's syndrome: the practical implications of recent psychological research. In: Down's Syndrome: A Review of Current Knowledge (eds J.A. Rondal, J. Perera \& L. Nadel), pp. 99-110. Whurr Publishers, London.

Cicchetti D.V. (1994) Guidelines, criteria, and rules of thumb for evaluating normed and standardized assessment instruments in psychology. Psychological Assessment 6, 284-290.

Cohen J. (1960) A coefficient of agreement for normal scales. Educational and Psychological Development 20, 37-46.

Cuskelly M. \& Dadds M. (1992) Behavioural problems in children with Down's syndrome and their siblings. Journal of Child Psychology \& Psychiatry \& Allied Disciplines 33, 749-761.

Davies M., Howlin P. \& Udwin O. (1997) Independence and adaptive behavior in adults with Williams syndrome. American Journal of Medical Genetics 70, 188-195.

Davies M., Udwin O. \& Howlin P. (1998) Adults with Williams syndrome. British Journal of Psychiatry 172, 273-276.

Don A.J., Schellenberg E. \& Rourke B.P. (1999) Music and language skills of children with Williams syndrome. Child Neuropsychology 5, 154-170.

Dykens, E.M. (1995) Measuring behavioral phenotypes: provocations from the"new genetics". American Journal on Mental Retardation 99, 522-532.

Dykens E.M. (2002) Are jigsaw puzzle skills "spared" in persons with Prader-Willi syndrome? Journal of Child Psychology $\mathcal{E}$ Psychiatry \& Allied Disciplines 43(3), 343-352.

Dykens E.M. (2003) Anxiety, fears, and phobias in persons with Williams syndrome. Developmental Neuropsychopathology 23, 291-316.

Dykens E.M. \& Cassidy S.B. (1996) Prader-Willi syndrome: genetic, behavioral, and treatment issues. Child and Adolescent Psychiatric Clinics of North America 5, 913-927.

Dykens E.M. \& Kasari C. (1997) Maladaptive behavior in children with Prader-Willi syndrome, Down's syndrome, and non-specific mental retardation. American Journal on Mental Retardation 102, 228-237.

Dykens, E.M. \& Rosner, B.A. (1999) Refining behavioral phenotypes: personality-motivation in Williams and PraderWilli syndromes. American Journal on Mental Retardation 104, 158-169. 
Dykens E.M., Hodapp R.M., Walsh K.K. \& Nash L.J. (1992) Profiles, correlates, and trajectories of intelligence in PraderWilli syndrome. Journal of the Academy of Child and Adolescent Psychiatry 31, 1125-1130.

Dykens E.M., Hodapp R.M. \& Evans D.W. (1994) Profiles and development of adaptive behavior in children with Down's syndrome. American Journal on Mental Retardation 98, 580-587.

Dykens E.M., Hodapp R.M. \& Finucane B.M. (2000) Genetics and Mental Retardation Syndromes: A New Look at Behavior and Interventions. Paul H. Brookes, Baltimore, MD.

Dykens E.M., Rosner B.A. \& Ly T.M. (2001) Drawings by individuals with Williams syndrome: are people different from shapes? American Journal on Mental Retardation 106, 94-107.

Dykens E.M., Shah B., Sagun J., Beck T. \& King B.Y. (2002) Maladaptive behavior and psychiatric disorders in persons with Down's syndrome. Journal of Intellectual Disabilities Research 46, 484-492.

Einfeld S.L., Tonge B.J. \& Florio T. (1997) Behavioral and emotional disturbance in individuals with Williams syndrome. American Journal on Mental Retardation 102, 45-53.

Einfeld S., Tonge B., Turner G., Parmenter T. \& Smith A. (1999) Longitudinal course of behavioural and emotional problems of young persons with Prader-Willi, Fragile X, Williams and Down's syndromes. Journal of Intellectual $\mathcal{E}$ Developmental Disability 24, 349-354.

Fowler, A. (1990) Language abilities in children with Down's syndrome: Evidence for a specific syntactic delay. In: Children with Down's Syndrome: A Developmental Approach (eds D. Cicchetti \& M. Beeghly), pp. 302-328. Cambridge University Press, New York.

Freeman S.F.N. \& Hodapp R.M. (2000) Educating children with Down's syndrome: Service needs and new educational strategies. Down's syndrome Quarterly 5, 1-9.

Greenspan S. \& Granfield J.M. (1992) Reconsidering the construct of mental retardation: Implications of a model of social competence. American Journal on Mental Retardation 96, 442-453.

Harris N.G.S., Bellugi U., Bates E., Jones W. \& Rossen M. (1997) Contrasting profiles of language development in children with Williams and Down's syndromes. Developmental Neuropsychology 13, 345-370.

Hodapp R.M. \& Dykens E.M. (1994) Mental retardation's two cultures of behavioral research. American Journal on Mental Retardation 98, 675-687.

Hodapp R., Dykens E.M. \& Masino L. (1997) Families of children with Prader-Willi syndrome: Stress-support and relations to child characteristics. Journal of Autism \& Developmental Disorders 27, 11-24.

Hodapp R.M., Evans D.W. \& Gray F.L. (1999) What we know about intellectual development in children with Down's syndrome. In: What do we Know About Down's syndrome? A Review of Current Knowledge (eds J. Rondal, J. Perera \& L. Nadel), pp. 124-132. Whurr, London.

Hornby G. (1995) Father's view of the effects on their families of children with Down's syndrome. Journal of Child and Family Studies 4, 103-117.

Kaufman A.S. \& Kaufman N.L. (1983) Kaufman Assessment Battery for Children. American Guidance Service, Circle Pines, $\mathrm{MN}$.

Levitan D.J. \& Bellugi U. (1998) Musical abilities in individuals with Williams syndrome. Music Perception 15, 357-398.

Mervis C.B., Klein-Tasman B.P. \& Mastin M.E. (2001) Adaptive behavior of 4- through 8-year-old children with Williams syndrome. American Journal on Mental Retardation 106, 82-93.

Miller J., Leddy M., Miolo G. \& Sedey A. (1995) The development of early language skills in children with Down's syndrome. In: Down's Syndrome: Living and Learning in the Community (eds L. Nadel \& D. Rosenthal), pp. 115-120. Wiley-Liss, New York.

Plissart L. Borghgraef M., Volcke P., Van den Berghe H. \& Fryns J.P. (1994) Adults with Williams-Beuren syndrome: evaluation of the medical, psychological, and behavioral aspects. Clinical Genetics 46, 161-167.

Rigby A.S. (2000) Statistical methods in epidemiology. V. Towards an understanding of the kappa coefficient. Disability and Rehabilitation 22, 339-344.

Siperstein G. (1992) Social competence: an important construct in mental retardation. American Journal on Mental Retardation 96, iii-vi.

Udwin O. \& Yule W. (1990) Expressive language of children with Williams syndrome. American Journal of Medical Genetics 6, 108-114.

Udwin O., Howlin P., Davies M. \& Mannion E. (1998) Community care for adults with Williams syndrome: How families cope and the availability of support networks. Journal of Intellectual Disability Research 42, 238-245.

Widaman K.F., MacMillan D.L. Hemsley R.E., Little T.D. \& Balow, I.H. (1992) Differences in adolescents' self-concept as a function of academic level, ethnicity, and gender. American Journal on Mental Retardation 96, 387-403.

Williams G.A. \& Asher S.R. (1992) Assessment of loneliness at school among children with mild mental retardation. American Journal on Mental Retardation 96, 373-385.

Wishart J.G. \& Johnston F.H. (1990) The effects of experience on attribution of a stereotyped personality to children with Down's syndrome. Journal of Mental Deficiency Research 34, 409-420.

Zigler E. \& Trickett P. (1978) IQ, social competence, and evaluation of early childhood intervention programs. American Psychologist 33, 789-798. 